Artigos

\title{
Religião e futebol no Brasil
}

\author{
Análise do "fechamento"
}

\author{
Religion and football in Brazil \\ Analysis of the "fechamento" \\ Religión y fútbol en Brasil \\ Un análisis del "fechamento"
}

Claude Petrognani ${ }^{1}$

\begin{abstract}
Resumo: O "fechamento" consiste numa prática comum entre os jogadores brasileiros. É realizada no interior do vestiário, mas não só, antes das partidas. Ela exige uma performance corporal própria dos jogadores e a reza coletiva, estrondosa e em uníssono, do Pai Nosso católico. Esta prática reveste-se de intensa densidade simbólica uma vez que ela galvaniza e condensa as principais mentalidades religiosas que compõem o pluralismo religioso brasileiro. O "fechamento" se inscreve, ainda que não diretamente, a práticas religiosas trazidas para dentro do mundo esportivo, sobretudo futebolístico, pelo grupo religioso Atletas de Cristo, sobre o qual este texto também irá discorrer.
\end{abstract}

Palavras-chave: Religião; Futebol.; "Fechamento".

Abstract: The "fechamento" (closure) is a common practice among Brazilian footballers. It takes place inside the dressing room, but not only, just before the matches. It requires a body performance specific to footballers and the collective prayer, resounding and in unison, of the catholic "Our Father's". This practice assumes an intense symbolic density because it galvanizes and condenses the main religious mentalities, which make up Brazilian religious pluralism. The "fechamento" is related, even if not directly, to the religious practices introduced in the world of sport, especially football, by the religious group "Athletes of Christ", about which it will also be question in this text.

Keywords: Religion; Soccer; "Fechamento"; Brazil.

Resumen: El "fechamento" consiste en una práctica común entre los futbolistas brasileños. Se realiza dentro del vestuario, pero no solo, antes de los partidos. Ella exige una performance corporal propia de los futbolistas y la oración colectiva, estruendosa y al unísono, del Padre Nuestro católico. Esta práctica adquiere una intensa carga simbólica, ya que galvaniza y condensa las principales mentalidades religiosas que componen el pluralismo religioso brasileño. El "fechamento" encaja, aunque no directamente, en prácticas religiosas traídas dentro del mundo deportivo, sobre todo futbolístico, por el grupo religioso Atletas de Cristo, sobre el cual este texto también discurre.

Palabras clave: Religión; Fútbol; "Cierre”; Brasil.

${ }^{1}$ École Pratique des Hautes Études (EPHE, Paris-Sorbonne, France). autor.dados_biográficos

Civitas, Porto Alegre, v. 19, n. 1, p. 247-260, jan.-abr. 2019

Este artigo está licenciado sob forma de uma licença Creative Commons Atribuição 4.0 Internacional, que permite uso irrestrito, distribuição e reprodução em qualquer meio, desde que a publicação original seja corretamente citada. https://creativecommons.org/licenses/by/4.0/deed.pt BR 


\section{Introducão}

Este texto versa sobre a aproximação entre religião e futebol no Brasil, mais especificamente, sobre uma prática aparentemente secundária chamada, emicamente, no mundo do futebol, de "fechamento". ${ }^{1}$ Realizada pelos jogadores no interior do vestiário, mas não só, antes das partidas, ela consiste numa reza coletiva, estrondosa e em uníssono, do Pai Nosso católico, estando, nesta ocasião, todos os jogadores reunidos em círculo e apertando fortemente as mãos uns dos outros. Esta prática reveste-se de uma grande densidade simbólica uma vez que ela galvaniza e é capaz de condensar as principais mentalidades religiosas que compõem o pluralismo religioso brasileiro.

Trata-se de uma prática típica dos jogadores de futebol, que alcança também outros esportes, sobre a qual, até onde conhecemos, até o momento somente Arlei Damo se ocupou, no capítulo "Os ritos e performances de pertencimento antes do jogo", em sua tese de doutorado em antropologia (Damo, 2007 [2005]). Nesse capítulo, Damo analisa o "fechamento" como um ritual de pertencimento cuja função seria a de fortalecer e potencializar o espírito de grupo. Neste caso, o "fechamento" é tomado como um ritual que, como tantos outros, os esportistas executam em momentos emocionalmente intensos, antes das competições.

Pode-se pensar que esta prática é tão "natural" que passa despercebida e que as poucas vezes em que nela se fala (Damo, 2007) seja incluída na categoria dos rituais coletivos que os jogadores estão acostumados a realizar para "energizar-se" antes de enfrentar o adversário. A hipótese que sugerimos é que o "fechamento" pode ser lido como uma prática que congrega um conjunto de elementos provenientes dos horizontes de várias religiões (afro-brasileira, católica, evangélica), aproximando-se, assim, do fenômeno da bricolagem (Levi-Strauss, 1962), embora o antropólogo francês tenha utilizado este conceito para se referir à construção dos mitos.

Antes, porém, de nos debruçarmos especificamente sobre o "fechamento" vamos tecer algumas considerações sobre aproximações entre futebol e religião no Brasil através do grupo Atletas de Cristo.

\footnotetext{
${ }^{1}$ Parte substancial dos dados etnográficos utilizados no presente texto resultam da pesquisa de campo realizada pelo autor junto ao Sport Club Internacional, de Porto Alegre, entre os anos de 2012 e 2015, e que oportunizaram a defesa de uma tese de doutorado defendida junto ao Programa de Pós-Graduação em Antropologia Social da Universidade Federal do Rio Grande do Sul, no ano de 2016, sob a orientação de Ari Pedro Oro.
} 


\section{Religião e futebol no Brasil}

No Brasil, tornou-se uma prática "naturalizada" a demonstração aberta de parte dos jogadores de futebol das suas religiosidades, rezando dentro e fora do campo, apelando a Deus e agradecendo a ele após um gol, um pênalti, ${ }^{2}$ uma vitória, mas também depois de uma derrota, isto porque, como dizem, "Deus é fiel"3 (na boa como na má sorte), testemunhando a própria fé em entrevistas, revistas, ${ }^{4}$ eventos profanos, ${ }^{5}$ uma fé que dizem ajudar a vencer "na vida como no esporte". Porém, assim procedendo, como se sabe, os jogadores e os clubes de futebol - estão desrespeitando as regras de neutralidade religiosa estabelecidas pela Federação Internacional de Futebol (Fifa), ${ }^{6}$ em âmbito

${ }^{2}$ Aguiar (2011) analisou o discurso que o então diretor do grupo Atletas de Cristo, sobre o qual falaremos a seguir, Alex Ribeiro, fez por ocasião da Copa do Mundo de 1994, quando o Brasil conquistou o tetra campeonato mundial de futebol. Na versão de Ribeiro (1995), a conquista era interpretada pela ótica da religião, ou melhor, pela ótica da supremacia da fé evangélica. Como recorda justamente Aguiar (2011, p. 229) "a seleção de futebol do Brasil [...] contava com seis atletas 'evangélicos' [...] que encontraram uma explicação sui generis para a conquista do título: Deus". Dentro desta perspectiva o pênalti (emblemático, dramático, performático) que Baggio perdeu foi traduzido em uma disputa entre Buda (Baggio ainda hoje é o esportista mais conhecido que se converteu ao budismo) e Cristo (Taffarel evangélico e Atleta de Cristo).

3 A expressão "Deus é fiel", assim como o ato de se ajoelhar apontando para o céu em gratidão a uma suposta benção, "tornou-se comum entre jogadores evangélicos" (Aguiar, 2011, p. 242). Consideramo-la como um indicador de uma evangelização difusa, banal e silenciosa (Rial, 2012), em ato no meio esportivo, em particular futebolístico, com impacto social e político. Não se trata de uma expressão "neutra", mas, de acordo com Giumbelli (2004, p.47), estaria associada "com indícios de religiosidade pública - algo que se associa a expansão dos evangélicos nas últimas duas décadas no Brasil".

${ }^{4}$ A este respeito, pode-se consultar a revista on-line Atletas de Cristo (www.atletasdecristo.org/ jornal). Por ocasião da Copa do Mundo de 2014 houve também a entrega gratuita, nas praças da cidade de Porto Alegre, uma das sedes da Copa, de cópias do Evangelho de João revisitado em chave esportiva. A capa do livro representava uma mão que segurava uma medalha, a qual, em sua volta, estava irradiada uma luz branca/amarela. Pouco abaixo da capa, emoldurada num provável gramado de futebol, se anunciava: "Vencedor. O Evangelho de João com testemunhos de grandes atletas". Folhando o livro, o leitor se depara com testemunhos de jogadores de futebol, como por exemplo Hernanes, atualmente jogando na Hebei China Fortune, China; Fábio, goleiro do Cruzeiro; Falcão, famoso jogador de futebol de salão; Lúcio, atualmente zagueiro do Fc Goa (Índia), entre outros. Todos integram a associação evangélica Atletas de Cristo.

${ }^{5}$ É o caso, por exemplo, da Associação dos Homens de Negócio do Evangelho Pleno (Adhonep). No site da associação (www.adhonep.com) encontram-se testemunhos de jogadores profissionais. Uma análise da associação, assim como do testemunho do então jogador do Grêmio Zé Roberto, hoje no Palmeiras, está disponível em C. Petrognani (2014).

${ }^{6}$ A Fifa, após as comemorações da seleção brasileira, por ocasião da conquista da copa das confederações, em 2009, afirmou que não permitiria mais mensagens religiosas durante os jogos das suas competições. Segundo o diretor da Associação Dinamarquesa de Futebol, Hansen, entidade filiada à Fifa, "a religião não tem lugar no futebol", acrescentando que "misturar religião e esporte daquela maneira foi quase criar um evento religioso em si. Da mesma forma que não podemos deixar a política entrar no futebol, a religião também precisa restar fora" (disponível em www.noticias.gospelmais.com.br). A questão, entretanto, continua sendo discutida. $\mathrm{Na}$ Europa (em particular na França) as restrições possuem como objetivo limitar, muito mais do que entre os "evangélicos", as manifestações públicas da religião islâmica (Pfister, 2011), sendo esta, como se sabe, a segunda religião da França, depois do catolicismo (Baubérot, 2011, p. 66). 
internacional, e pela Confederação Brasileira de Futebol (CBF), ${ }^{7}$ em âmbito nacional.

Porém, a maior visibilidade religiosa no futebol brasileiro ocorre a partir dos anos 1980 através do grupo evangélico denominado Atletas de Cristo. ${ }^{8} \mathrm{Tal}$ presença religiosa no âmbito futebolístico coincide com o "aumento meteórico das igrejas evangélicas no Brasil” (Rial, 2013, p. 19). Ela ocorre através dos gestos em campo de agradecimento a Deus, de inscrições de palavras sagradas em suas camisetas (Deus é minha força, Deus é fiel, Obrigado a Jesus, Eu pertenço a Jesus), referências a Deus e a Jesus Cristo em entrevistas, depoimentos e testemunhos. Quem não lembra o jogador Kaká, depois do Brasil vencer a Copa do Mundo 2002, ajoelhado, no meio campo, ostentando a camiseta que portava os dizeres: "Eu pertenço a Jesus"? Ou, depois da final vencida pelo Brasil na África do Sul, na Copa das Confederações, além dos inúmeros gestos que invocam o transcendente nos gramados de futebol brasileiros? Segundo a antropóloga Rial (2013), esses gestos simbólicos promovem crenças religiosas em escala global, como um tipo de "religiosidade banal". O futebol, através da mídia, funcionaria, assim, como uma grande caixa de ressonância, permitindo uma visibilidade em escada global da fé evangélica (Rial, 2008).

Para uma análise detalhada acerca desta problemática que envolve, mais especificamente, as relações entre religião, futebol e espaço publico, ver Petrognani (2015).

${ }^{7} \mathrm{O}$ caso brasileiro é muito interessante. A Confederação Brasileira de Futebol (CBF), em 2012, se alinhou com as normas estabelecidas pela Fifa de proibir, limitar, as manifestações religiosas dentro e fora do campo. O diretor da CBF André Sanches, ex-presidente do Corinthians, em entrevista ao jornal Folha de São Paulo (disponível em: www.noticias.gospelmais.com.br), declarou: "A religião não atrapalha, mas acho que as pessoas devem fazer as coisas dentro do seu quarto. O que não pode é eu ser católico e te obrigar a ser católico". No entanto, apesar das restrições estabelecidas, manifestações religiosas continuam sendo praticadas de forma "banal" (Rial, 2012), por vezes de forma silenciosa, mas não por isso menos eficaz. É o caso, entre tantos, do goleiro do Sport Club Internacional de Porto Alegre (hoje na Roma Calcio) e da seleção brasileira Alisson, o qual, antes do apito inicial, tem o costume de se ajoelhar em frente à goleira, levantando os braços ao céu e orando. Os atletas das categorias de base do Internacional, que Petrognani acompanhou durante sua pesquisa de doutorado, costumam reproduzir este tipo de performance, sem, todavia, lhe conferir significado estritamente "religioso". Dito diferentemente, essencializam o discurso em chave cultural, afirmando se tratar de manifestações culturais brasileiras. A este respeito o estudo de Giumbelli (2012) recupera este tipo de debate culturalista que os religiosos utilizam para defender a presença de símbolos religiosos no espaço público. Além disso, em torno desta controvérsia podemos acrescentar que, se na Europa, de alguma forma, as restrições que a Fifa e a Uefa impõem nos seus estatutos não diferem de uma ideia de laicidade que corresponderia àquela francesa, ou seja, de limitações, e não propriamente proibições de manifestações e de símbolos religiosos nos espaços públicos (Diotallevi, 2015), a CBF, querendo aplicar este tipo de modelo europeu de laicidade, recusa, implícita ou explicitamente, as especificidades de uma laicidade à brasileira (Oro, 2011; Mariano, 2011).

${ }^{8}$ Sobre os Atletas de Cristo ver Jungblut (1994) e Aguiar (2011). As informações sobre o surgimento desse grupo podem ser também obtidas na página oficial do ADC na Internet (www.atletasdecristo.com.br). De acordo com Aguiar (2011, p.232), "Hoje ADC (Atletas de Cristo) conta com mais de seis mil atletas brasileiros, atuando no Brasil e em dezenas de países (Argentina, EUA, Portugal, Espanha, França, Itália, Turquia, Japão etc.)”. 
AAssociação Atletas de Cristo pode ser vista como integrando a tendência evangélica denominada neopentecostal. ${ }^{9}$ Ela surgiu no Brasil na década de 1980, graças a um então atleta de futebol do Clube Atlético Mineiro, João Leite (Aguiar, 2011). De acordo com Aguiar (2011, p. 231): “Apenas em 1981, com a criação de um grupo de apoio formado com gente suficiente para suportar o nascimento de uma instituição, é que o nome "Atletas de Cristo [...]", sugerido por Eliana Aleixo, na época estrela do vôlei brasileiro e esposa de João Leite, “[...] passa a denominá-los" (Aguiar, 2011, p. 231). Mais de trinta anos após o seu surgimento, os Atletas de Cristo, em razão do seu crescimento numérico, também para além das fronteiras nacionais, com a fixação de ministérios no exterior, ${ }^{10}$ conhecem um grande sucesso. O jogador Kaká pode, talvez, ser considerado, na atualidade, o representante mais famoso mundialmente dos Atletas de Cristo.

O grupo dos Atletas de Cristo possui o objetivo de recombinar práticas religiosas e atividades esportivas. Ou seja, ontem como hoje, o esporte se configura como um território de (re)conquista cristã, de renegociação de fiéis, em suma, um "canal por onde passa a palavra de Deus" (www.atletatsdecristo.org).

No site atletasdecristo.org está assim resumido o objetivo dos Atletas de Cristo:

Hoje o esporte é de fundamental importância no mundo e consequentemente no Brasil, são milhares de praticantes em nosso país [...] atletas surgindo a todo momento. Somos o país do futebol, do vôlei, da ginástica, da natação entre tantos outros, prova de que o esporte tem alcançado outros adeptos com habilidades distintas além do querido futebol, este por sua vez temos que ressaltar: é o esporte com mais ênfase no Brasil e que abre grandes portas no mundo inteiro. Entendemos tudo isto de maneira benéfica e por que não dizer oportuna para a pregação do evangelho da salvação, temos intensificado nossos esforços, nossas ações, e nossos melhores dias para tornar o esporte um grande canal por onde passa a Palavra de Deus e alcança os corações dos mais apaixonados e praticantes esportivos do Brasil e do mundo. [...] Seja um Atleta de Cristo.

\footnotetext{
${ }_{9}$ Pela expressão neopentecostalismo entendemos "aquela parcela do pentecostalismo surgido no Brasil a partir da década de 70 e que, sendo de difícil conceituação, recebeu denominações diferentes segundo os autores: 'agência de cura divina' (Monteiro, 1979), 'sindicato dos mágicos' (Jardilino, 1994), 'pentecostalismo de segunda e terceira ondas' (Freston, 1993), 'neopentecostalismo' (Mariano, 1995), 'pós-pentecostalismo' (Siepierski, 1997)” (Oro, 2003, p.205).Trata-se de uma tendência evangélica que segue os preceitos do pentecostalismo tradicional, especialmente a ênfase na figura do Espírito Santo e aos seus dons, mas que aciona, também, as teologias da guerra espiritual e da prosperidade, além de enfatizar a necessária presença religiosa no espaço público.

${ }^{10} \mathrm{Na}$ Itália, por exemplo, os Atletas de Cristo surgiram em 1998 com os então jogadores de futebol, Paulo Sergio (Roma) e Paulo Pereira (Genoa), ambos brasileiros (www.atletidicristo.org).
} 
A aproximação entre religião e esporte realizada pelos Atletas de Cristo não é única e exclusiva do Brasil. Com efeito, de um ponto de vista histórico sempre houve uma recíproca relação entre esporte e religião e vice-versa. Em outras palavras, religião e esporte sempre se "serviram" mutuamente. É suficiente pensar no movimento conhecido como Muscular Christianity (Mcloed, 2004; Parker e Watson, 2011; Martelli e Porro, 2013), o qual deita as suas origens na época da Inglaterra Vitoriana (1837-1901), período de transições entre os esportes tradicionais e o surgimento dos esportes modernos (Elias, 1986; Guttmann, 1978; Darbon, 2008). Tratava-se de uma associação de marca anglicana, que nasceu nos colégios das elites da época, as Public schools (Darbon, 2008), servindo-se do esporte como instrumento pedagógico, "civilizatório", como diria Elias (1986), e, de um ponto vista político, valendose de uma teologia de vanguarda como instrumento de "reconquista de fieis" (Mcloed, 2004).

Tanto o grupo Atletas de Cristo quanto a Muscular Christianity possuem em comum o interesse de fazer do esporte um palco de pregação e de conquista de fieis.

\section{O "fechamento"}

Usualmente, o "fechamento" é realizado no vestiário. Como pudemos constatar, do ponto de vista religioso o vestiário de um time de futebol brasileiro é sincrético. Dentro dele é comum existir uma espécie de altar, ou, ao menos, um local onde se pode encontrar imagens de santos católicos e também, em alguns casos, de entidades do panteão afro-religioso. Como relata Evanea Scopel, ${ }^{11}$ a psicóloga do Sport Club Internacional de Porto Alegre, que possui uma vasta trajetória profissional em outros times de futebol:

Em todos os clubes que trabalhei, nos vestiários dos times profissionais tem um pequeno altar. Este altar é como se fosse uma grutinha, pequena. Ela fica na altura, redondinha, e lá tem todas as manifestações religiosas possíveis de cada um. Tem Nossa Senhora Aparecida, têm os vários santos, tem a imagem de Jesus Cristo, tem balas e oferendas que tem a ver com a umbanda, o candomblé. Tem a parte das imagens e tem a parte das oferendas. Então tu vês que tem coisas diferentes, velas acesas... pedaços de orações (Entrevista, Evanea Scopel, 2013).

O "fechamento" consiste em um conjunto de atos, gestos, expressões detentores de forte valor simbólico - distintas de outras práticas seme-

\footnotetext{
${ }^{11} \mathrm{O}$ pronunciamento foi feito em data 17/10/2013. A entrevista completa é disponível em: <www. lume.ufrgs.br/handle/10183/156406>.
} 
lhantes ${ }^{12}$ - que fundamentalmente gira em torno da recitação coletiva da reza do Pai Nosso. Para se ter uma ideia desta prática basta reportar-se imaginariamente ${ }^{13}$ para dentro de um vestiário de um time de futebol poucos instantes antes do início da partida. Ali pode-se ver os jogadores e a comissão técnica reunidos no centro do vestiário, abraçando-se ou dando-se as mãos, formando um círculo. Ouvir-se-á o técnico e o capitão do time incentivando e impulsionando os seus companheiros para o "sacrifício" (simbólico) que os aguarda. Após isto, os jogadores, independentemente dos próprios pertencimentos religiosos, entoarão, em uníssono e com veemência, a oração do Pai Nosso. Trata-se do momento mais emblemático da transcendência, o momento mais sublime e intenso do ritual, no qual estoura toda a potência do sagrado. Na sequência, os jogadores "quebrarão" o círculo, por eles comumente chamada de "roda", e se exaltarão e exibirão, dando pulos desordenados e tapas nos ombros uns dos outros. Quebra-se a roda, mas, logo em seguida, a ordem é restabelecida. Então o grupo dos "onze eleitos" reconstitui o círculo. Agora eles estão novamente muito próximos uns dos outros. Eles "fecham" entre si, se juntam de mãos dadas, quase se tocando em seus rostos. Desta vez celebra-se o nome do clube, em voz alta. Mas tudo será interrompido poucos segundos mais tarde quando será restabelecida a ordem dentro do vestiário e os jogadores se colocam em fila para ingressar no gramado.

A explosão, a pleno pulmão, da oração que caracteriza o "fechamento" é o momento mais sublime, intenso e importante do ritual. O Pai Nosso é recitado, declamado, cantado, gritado, em uníssono e sincronicamente, de olhos fechados e com um vigor incrível, ritualizado dentro de um esquema fixo, mas, não por isso, menos performático. Muito pelo contrário, a oração incentiva um estado de excitação para quem partilha dessa espécie de "transe"14 que está em curso. Ao término da reza/canto é notável o estado de ânimo modificado

\footnotetext{
${ }^{12} \mathrm{Na}$ Itália, por exemplo, Petrognani (2010) constatou, durante a sua dissertação de mestrado, que existe uma prática semelhante que, porém, não prevê nenhum tipo de referência com o transcendente.

${ }^{13}$ Para se ter uma ideia mais precisa e detalhada, pode-se consultar a tese de doutorado de Petrognani (2016), disponível em: <www.lume.ufrgs.br/handle/10183/156406>.

${ }^{14} \mathrm{O}$ conceito de "transe" é, como escreveu o antropólogo italiano Barba (2016, p. 23) "un concetto mutato dalle religioni che prevedono la "possessione", ovvero la discesa di un' entità nel corpo di un fedele $[. .$.$] in più nelle religioni di possessione, lo stato di "trance" è un$ comportamento culturalmente appreso, come ben detto da Bastide (1979)". Quando falamos de "transe", portanto, estamos conscientes de estar forçando um conceito "complexo" do mundo das religiões que preveem a possessão. Ao falar aqui em "transe" estamos remetendo a um momento muito particular do "fechamento" que se caracteriza, pelo menos ao nível teatral, com performances que podem recordar, por analogia e correspondência, aquelas realizadas sobretudo pelos adeptos das religiões afro-brasileiras, mas também, até certo ponto, pelos pentecostais e neopentecostais.
} 
dos jogadores que participaram do "fechamento". Isto porque o vestiário, o lugar em que ocorreu a liturgia, tornou-se um lugar sagrado e eles produziram e participaram do momento de "efervescência coletiva", apesar da diferença de crenças existente entre eles. Assim, saem do ritual enquanto seres humanos satisfeitos e felizes por estarem juntos, por formarem uma communitas, em nome de Jesus.

Defendemos a ideia de que o "fechamento" tornou-se uma regra (não escrita) do futebol brasileiro, sendo hoje até mesmo ensinado nas escolinhas de futebol, como é o caso da escola Rubra, do Sport Club Internacional de Porto Alegre, e também no exterior (como é caso da escolinha de futebol fundada no Japão pela mesma equipe do Internacional) tendo encontrado lá grande sucesso. A partir destas considerações pode-se até mesmo se considerar o "fechamento", hoje, como um produto da cultura esportiva brasileira.

É importante destacar que no dia das partidas realizam-se ainda outras formas de "fechamento" além do mencionado nos vestiários. Muitas equipes "fecham" antes e depois do jogo. O sentido do "fechamento" final é de agradecimento por tudo o que aconteceu na partida. Como refere Ademir Calovi, ${ }^{15}$ o coordenador das categorias de base do Sport Club Internacional de Porto Alegre:

O que é comum é de "fechar" antes e depois do jogo, com dois sentidos: antes do jogo de unificar, globalizar e centralizar o esforço, e o segundo, de encerramento, para agradecer tudo o que aconteceu durante a partida. Os dois ["fechamentos"] terminam com a reza do Pai Nosso, sempre (Entrevista, Ademir Calovi, 2014).

A eficácia dos "fechamentos", antes e depois do jogo, é, portanto, dupla: fortalecer e potencializar o espírito do grupo, antes da competição, e, no final, potencializar ainda mais a união de "grupo", tendo a equipe sido vitoriosa ou derrotada. Isto significa que, paradoxalmente, muitas vezes o último "fechamento" da série é mais importante frente a situações de sofrimentos (derrotas, lesões etc.). Obviamente, é muito mais simples "aceitar" uma vitória do que uma "derrota". Portanto, o "fechamento" final torna-se mais significativo quando se trata de metabolizar situações adversas, encontrando, assim, na derrota e em situações de forte desconforto, como lesões, um sentido positivo. Em outras palavras, o ritual possui a função de traduzir o desconforto em conforto. Isto, porém, como afirma Geertz (1989 [1973]), encontra a

\footnotetext{
${ }^{15} \mathrm{O}$ pronunciamento foi feito em data 11/11/2014. A entrevista completa é disponível em: <www. lume.ufrgs.br/handle/10183/156406>.
} 
sua solução justamente porque o sofrimento é enfrentado como "problema religioso". Neste caso,

O problema do sofrimento é, paradoxalmente, não como evitar o sofrimento, mas como sofrer, como fazer da dor física, da derrota frente ao mundo ou da impotente contemplação da agonia alheia algo tolerável, suportável, sofrível, se assim podemos dizer (Geertz, 1989, p. 76).

Desta forma, parafraseando Geertz (1989, p. 76) poderíamos dizer que o "fechamento" final de agradecimento é eficaz não porque evita o sofrimento, mas porque faz do sofrimento algo suportável "se assim podemos dizer".

É importante destacar, também, que o "fechamento" pode ser realizado dentro do campo de futebol. Assim sendo, se em princípio o "fechamento" poderia ser considerado uma prática privada, ele está se tornando cada vez mais público em razão também das gravações feitas e postadas nos canais Youtube.${ }^{16}$ Além disso, trata-se de uma prática realizada por diferentes coletivos futebolísticos, não somente por profissionais, mas também por amadores, de diferentes faixas etárias.

Por fim, e muito importante, o "fechamento", em razão da sua plasticidade e performance, torna-se uma espécie de caleidoscópio, ao concentrar, galvanizar e conter em si elementos e dispositivos passíveis de entendimentos e leituras provenientes dos principais horizontes que formam $\mathrm{o}$ pluralismo religioso brasileiro. Assim, os católicos "fecham" rezando uma das mais tradicionais, principais e importantes orações do seu repertório religioso, considerada a "oração do Senhor", a oração da igreja. Não por acaso, o Pai Nosso é, inclusive, recitado em todas as celebrações das missas e é tido como o modelo e padrão de oração. Já os que se identificam como pentecostais, neopentecostais, ou mesmo como evangélicos, ao "fecharem" recitam a oração "que o Senhor nos ensinou", inscrevendo-a, porém, em sua cosmovisão religiosa que, baseada no princípio maniqueísta, confere às forças demoníacas um grande poder na produção das aflições, sendo, por isso mesmo, necessário exorcizá-las. Neste sentido, os jogadores que compartilham a mentalidade pentecostal executam a performance corporal própria deste meio religioso. $\mathrm{Ou}$ seja, com as mãos dadas entre si, ou erguidas, olhos fechados, corpos trêmulos, oram, com energia e muita força, o Pai Nosso como uma espécie de "oração de guerra", para exorcizar os demônios presentes no vestiário e nos corpos dos atletas para, desta forma, serem vitoriosos na partida que irão disputar.

\footnotetext{
${ }^{16}$ Ver, por exemplo, Palmeiras: filme Libertadores.
} 
Enfim, o "fechamento", como dissemos, é também chamado de "roda" e, neste sentido, dialoga com outra importante expressão religiosa nacional, as chamadas religiões afro-brasileiras. Nestas a "roda" é formada no início das cerimônias que ocorrem nos terreiros, reunindo os membros que participam ativamente do ritual e que irão receber os orixás ou outras entidades espirituais. Nos rituais em que é celebrada a "balança do Xangô" os "rodantes", colocados lado a lado, formam uma roda, se dão firmemente as mãos e dançam ao ritmo dos tambores que vão gradualmente aumentando de intensidade. Enquanto isto as possessões vão ocorrendo. Nestas ocasiões, como destaca Barbàra (2003, p. 61):

A roda simboliza a grande mãe terra, que contém no seu ventre o universo e exprime um ideal de perfeição, de imutabilidade, mas também de transformação, porque possui em si os elementos masculinos e femininos [...] a roda é o símbolo do movimento circular, da evolução, da vida que continua [...] indica que a divindade está possuindo a filha de santo".

Assim sendo, os adeptos ou simpatizantes do campo afro-religioso que participam do "fechamento" encontram nele similaridades com as rodas executadas nos terreiros.

Aliás, é possível que os jogadores e mesmo dirigentes ou funcionários de um clube de futebol que possuem familiaridade com o campo afroreligioso e que acessam os vestiários e participam do "fechamento" vejam outras aproximações entre o futebol e aquele campo religioso. É o que sugere o antropólogo italiano Barba (2007), que apontou cinco analogias possíveis entre eles, a saber: 1) O vestiário seria o "terreno", lugar onde os jogadores se preparam e se energizam assim como o "terreiro" é o espaço onde o grupo de candomblé realiza os rituais; 2) a imagens figuram nos vestiários e nos centros de formação dos times profissionais. Podem ser imagens ou quadros religiosos mas também fotografias de vitórias ou dos ídolos que fizeram a "história" do clube, da mesma forma como um terreiro de candomblé está sempre decorado com imagens dos orixás e dos fundadores da casa do culto. Segundo Barba, haveria, tanto no clube quanto no grupo de candomblé, um forte sentido de "família"; 3) um lugar "secreto": um time de futebol, como um terreiro de candomblé, possui espaços que os "estranhos" não podem "visitar"; 4) o presidente de um time de futebol, segundo Barba (2007, p. 66) pode ser comparado à figura do pai ou mãe de santo, tendo características semelhantes, como o carisma, a experiência, capacidades psicológicas, coragem e disponibilidade financeira. 


\section{Conclusão}

Este texto procurou apresentar uma prática muito difundida no futebol brasileiro. Analisamos o "fechamento" menos na perspectiva funcionalista ou em termos "durkheimianos", e mais como um conjunto de expressões simbólicas que foram se "construindo" e se "juntando" ao longo do tempo, através das quais os jogadores brasileiros se servem para reproduzir uma determinada visão de mundo (Geertz, 1989), o que significa ver na maneira de "fechar" um verdadeiro fenômeno social (Mauss, 1950 [1936]). Mostramos, neste sentido, que: a) o "fechamento", ou "roda", é uma prática composta de expressões corporais e verbais considerada, na atualidade, como integrante da cultura esportiva brasileira; b) assim sendo, pode-se afirmar que o "fechamento", ou "roda", constitui um habitus ${ }^{17}$ do jogador de futebol brasileiro; enfim c) o " $\mathrm{fe}$ chamento", ou "roda", reveste-se de um conteúdo simbólico posto que firmouse, parafraseando Laplantine (2003), como um caleidoscópio próprio da cultura religiosa brasileira (Sanchis, 1997).$^{18}$ Isto tudo ajudaria a explicar o seu sucesso transversal, independentemente dos pertencimentos religiosos dos jogadores.

De fato, o "fechamento" pode ser lido como uma prática que se reveste de conteúdo católico, mas também afro-religioso, além de pentecostal e/ ou neopentecostal, esta última dimensão tendo sido agregada após o surgimento no meio esportivo brasileiro do grupo evangélico Atletas de Cristo. Desta forma, pode-se até mesmo afirmar que o "fechamento" possui, intrinsecamente, vários pedaços de diferentes religiões, embora a sua matriz dominante seja cristã. Ou seja, trata-se de um produto "sincrético", um sincretismo capaz de permitir a quem dele participar poder escolher, livremente, o que ser e o que ver nele. Neste sentido, o "fechamento" não está a serviço de uma religião, mas sim de todas elas.

\footnotetext{
${ }^{17}$ Noção com a qual Bourdieu (1989) indica um conjunto de expressões e de práticas que os indivíduos adquiriram e que, portanto, interiorizaram durante o seu percurso individual, e que produzem uma mesma visão de mundo.

${ }^{18}$ Sanchis (1997) fala de habitus religioso brasileiro. Com esta expressão entende a propensão, em relação às peculiares contingências históricas e sociais, brasileira ou pelo menos de parte delas, em desenvolver uma religiosidade inclusiva e cumulativa, acolhendo, criando e reelaborando conteúdos religiosos provenientes de universos diferentes, chamado, geralmente, de "sincretismo". A história nos diz que os povos indígenas, os escravos africanos logo depois, converteram-se, a maioria forçadamente, ao catolicismo, mas continuaram acreditando e cultuando os seus deuses. Esta propensão "antropofágica", capaz de reinterpretar pedaços de elementos provenientes de universos simbólico-culturais/religiosos diferentes "deu à luz" produtos sincréticos para os quais são famosos, entre outros: o Candomblé, a Umbanda (Bastide, 1970), a festa da Nossa Senhora dos Navegantes (Oro, Dos Anjos, 2008), a festa do Divino (Ferretti, 2007), o carnaval, a capoeira, o samba, o futebol (Da Matta, 1997), as religiões neopentecostais (Almeida, 2003; Oro, 2005; 2015; Silva, 2005; 2015).
} 


\section{Referências}

AGUIAR, Reinaldo Olécio. Deus é mais: a supremacia da fé evangélica na ótica dos Atletas de Cristo. Revista Brasileira de História das Religiões, v. 3, n. 9, p. 229-252, $2011<$ www.dhi.uem.br/gtreligiao/pdf8/11.pdf> (2 nov. 2016).

ALMEIDA, Ronaldo de. A guerra de possessões. In: André Corten; Jean-Pierre Dozon; Ari Pedro Oro (orgs.). Igreja Universal do Reino de Deus: os novos conquistadores da fé. São Paulo: Paulinas, 2003. p.321-342.

BARBA, Bruno. Calciologia: per una antropologia del football. Milano-Udine: Mimesis Edizioni, 2016.

BARBA, Bruno. Un antropologo nel pallone, Roma: Meltemi, 2007.

BARBÀRA, Susanna. Il Candomblé. Milano: Xênia Edizioni, 2003.

BASTIDE, Roger. Mémoire collective et Sociologie du bricolage. L'année sociologique, v. 21, p. 65-108, $1970<\mathrm{http}$ //classiques.uqac.ca/contemporains/bastide roger/memoire_collective_socio_bricolage/memoire_collective_socio_bricolage. pdf> (5 dez. 2016).

BAUBÉROT, Jean. Libertà religiosa e laicità in Francia. Lessico di etica pubblica, v. 2, n. 2, p. 59-70, $2011<w w w . e t i c a p u b b l i c a . i t / w p-c o n t e n t / u p l o a d s / 2014 / 10 / 22011-5$. pdf> (6 dez. 2016).

BOURDIEU, Pierre. O poder simbólico. Rio de Janeiro: Bertrand Editora, 1989.

DA MATTA, Roberto. Do pais do carnaval à carnavalização: o escritor e seus dois Brasis. Rio de Janeiro: Cadernos de Literatura Brasileira, 1997.

DAMO, Arlei Sander. Do dom à profissão: a formação de futebolistas no Brasil e na França. São Paulo: Hucitec, 2007.

DARBON, Sebastien. Diffusion des sport et impérialisme anglo-saxon: de l'histoire événementielle à l'anthropologie. Paris: Édition de la Maison des Sciences de l'Homme, 2008.

DIOTALLEVI, Luca. O sentido e o problema do "separatismo moderado": por uma contribuição sociológica à análise da religião no espaço público. Debates do Ner, v. 1, n. 27 , p. 19-48, $2015<10.1234$ /dner.v1i27.56459>.

ELIAS, Norbert. Sport and leisure in the civiling process. Oxford: Basil Blackwell, 1986.

FERRETTI, Sergio. Sincretismo e religião na festa do Divino. Revista Anthropológicas,

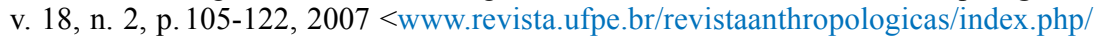
revista/article/view/144/129> (10 set. 2015).

GEERTZ, Clifford. Interpretação das culturas. Rio de Janeiro: GEN, 1989.

GIUMBELLI, Emerson. Crucifixos em recintos estatais e monumento do Cristo Redentor: distintas relações entre símbolos religiosos e espaços públicos. In: Carlos Alberto Steil; Roberto Cipriani; Emerson Giumbelli; Ari Pedro Oro (orgs.). A religião no espaço publico: atores e objetos. São Paulo: Terceiro Nome, 2012. p. 45-60.

GIUMBELLI, Emerson. Religião, estado, modernidade: notas a propósitos de fatos provisórios. Estudos Avançados, v. 52, p.47-62, $2004<10.1590 /$ S010340142004000300005>. 
GUTTMANN, Allen. From ritual to record: the nature of modern sports. New York: Columbia University Press, 1978.

JUNGBLUT, Airton Luiz. Entre o Evangelho e o futebol: um estudo sobre a identidade religiosa de um grupo de Atletas de Cristo em Porto Alegre. 1994. Dissertação (Mestrado em Antropologia Social), PPGAS-Ufrgs, Porto Alegre, 1994.

LAPLANTINE, François. Penser anthropologiquement la religion. Anthropologie et Sociétés, v. 1, n. 27, p. 11-33, $2003<$ www.erudit.org/revue/as/2003/v27/n1/007000ar. pdf> (25 maio 2017).

LÉVI-STRAUSS, Claude. La pensée sauvage. Paris: Plon, 1962.

MARIANO, Ricardo. Laicidade à brasileira: católicos, pentecostais e laicos em disputa na esfera pública. Civitas, v. 11, n. 2, p. 238-258, $2011<10.15448 / 1984-$ 7289.2011.2.9647>.

MARTELLI, Stefano; PORRO, Nicola. Manuale di Sociologia dello Sport. Milano: Franco Angeli, 2013.

MAUSS, Marcel. Les techniques du corps. In: Marcel Mauss (org.). Sociologie et anthropologie. Paris: Presses Universitaire de France, 1950. p.386-409.

MCLOED, Hugh. La religion et l'essor du sport en Grande-Bretagne. Revue d'histoire $d u$ XIX siècle, v. 28, p. 2-15, $2004<10.4000 /$ rh19.624>.

ORO, Ari Pedro. A laicidade no Brasil e no Ocidente: algumas considerações. Civitas, v. 11, n. 2, p. 221-237, $2011<10.15448 / 1984-7289.2011 .2 .9646>$.

ORO, Ari Pedro. Intolerância religiosa iurdiana e reações afro no Rio Grande do Sul. In: Vagner Gonçalves da Silva (org.). Intolerância religiosa: impacto do neopentecostalismo no campo religioso afro-brasileiro. São Paulo: Editora da Universidade de São Paulo, 2015. p. 29-69.

ORO, Ari Pedro. O neopentecostalismo macumbeiro. Revista USP, v. 68, p. 319-332, $2005<10.11606 /$ issn.2316-9036.v0i68p319-332>.

ORO, Ari Pedro; PETROGNANI, Claude, A laïcité em questão: um comentário a um texto de Luca Diotallevi. Debates do Ner, v. 1, n. 27, p. 51-61, $2015<10.22456 / 1982-$ 8136.56460>.

ORO, Ari Pedro; DOS ANJOS, José. Carlos. G., Festa de Nossa Senhora dos Navegantes em Porto Alegre: sincretismo entre Maria e Ienmanjà. Porto Algre: Editora da Cidade, 2008.

PARKER Andrew; WATSON, Nick. Sport, spiritualità e religione: "Muscular Christianity" e oltre. Religioni e società - Rivista di scienze sociali della religione, v. 26, n. 71, p. 61-69, 2011.

PETROGNANI, Claude. Estou aqui como um profeta de Deus: Zé Roberto, o futebol e a religiosidade como beliscão do destino. Debates do Ner, v. 15, n. 26, p. 229-252, $2014<$ https://seer.ufrgs.br/debatesdoner/article/download/52051/32088> (22 dez. 2018).

PETROGNANI, Claude. Avanço neopentecostal no futebol brasileiro: análise sócio-antropológica acerca das relações entre religião, futebol e espaço público no Brasil. El futuro nel Pasado, v. 6, p. 175-191, 2015 <10.14516/fdp.2015.006.001. $007>$. 
PETROGNANI, Claude. Futebol e religião no Brasil: um estudo antropológico do "fechamento". 2016. Tese (Doutorado em Antropologia Social), PPGAS-Ufrgs, Porto Alegre, $2016<$ www.lume.ufrgs.br/handle/10183/156406> (22 dez. 2018).

PETROGNANI, Claude. Il rituale è di rigore? Gesti, spazi e superstizioni di una squadra di calcio. 2010. Tesi (Laurea Specialistica Magistrale in Antropologia Culturale ed Etnologia), Unige, Genova (Italia), 2010.

PFISTER, Geltrud. Tra restrizioni ed empowerment. Islam e sport femminile. Religioni e Società-Rivista di scienze sociali della religione. v. 26, n. 71, p. 28-41, 2011.

RIAL, Carmen. "O ovo do diabo" e os jogadores de futebol como pastores neopentecostais, Revista Instituto Humanitas Unisinos, v. 13, n. 424, p. 19-22, $2013<$ www. ihu.unisinos.br/entrevistas/521272-o-ovo-do-diabo-e-os-jogadores-de-futebol-comopastores-neopentecostais-entrevista-especial-com-carmen-silvia-rial> (20 jan. 2017).

RIAL, Carmen. Banal religiosity: Brazilian athletes as new missionaries if the Neo-Pentecostal diaspora. Vibrant, v. 9, n. 2, p. 130-58, $2012<10.1590 /$ S180943412012000200005>.

RIAL, Carmen. Rodar: a circulação dos jogadores de futebol brasileiro no exterior. Horizontes Antropológicos, v. 14, n. 30, p. 21-65, $2008<10.1590 /$ S010471832008000200002>.

RIBEIRO, Alex Dias. Atletas de Cristo. São Paulo: Mundo Cristão, 1995.

SANCHIS, Pierre. As religiões dos brasileiros. Horizonte, v. 1, n. 2, p. 28-43, 1997 $<$ http://periodicos.pucminas.br/index.php/horizonte/article/view/412> (25 maio 2017).

SILVA, Vagner Gonçalves da. Entre a gira de fé e Jesus de Nazaré: relações socioestruturais entre neopentecostalismo e religiões afro-brasileiras. In: Vagner Gonçalves da Silva (org.) Intolerância religiosa: impacto do neopentecostalismo no campo religioso afro-brasileiro. São Paulo: Editora da Universidade de São Paulo, 2015. p. 171-189.

SILVA, Vagner Gonçalves da. Concepções religiosas afro-brasileiras e neopentecostais: uma análise simbólica. Revista USP, v. 67, p. 150-175, 2005 <www.revistas.usp.br/ revusp/article/view/13461/15279> (25 maio 2017).

Recebido: 15 maio 2018

Aceito: 23 nov. 2018

Publicado: 01 mar. 2019

Endereço do autor:

Claude Petrognani

Groupe Sociétés, Religions, Laïcités

GSRL UMR 8582 (EPHE-CNRS)

CNRS - Site d'Ivry-sur-Seine

27, rue Paul Bert

94204 Ivry-sur-Seine Cedex, France

Claude Petrognani < claude.petrognani@libero.it>

Doutor pelo PPG em Antropologia Social da Universidade Federal do Rio Grande do Sul (Ufrgs, Porto Alegre, RS, Brasil), bolsista de pós-doutorado na École Pratique des Hautes Études (EPHE) en Sciences Religieuses, ParisSorbonne, França.

Orcid: https://orcid.org/0000-0002-0694-0541 